\section{COMPARISON OF WIRELESS ADAPTERS INTERFERENCE BASED ON DIFFERENCES OF FLOOR POSITION}

\author{
Sasa Ani Arnomoa*, Yulia ${ }^{a}$, Noraini Ibrahim
}

aDepartment of Information System, Faculty of Engineering and Computers, Putera Batam University, Kepulauan Riau, Indonesia bFaculty Sciences Computer and Technology Information, Universiti Tun Hussein Onn Malaysia (UTHM), Johor, Malaysia
Article history

Received

14 December 2020

Received in revised form

19 May 2021

Accepted

8 June 2021

Published online

20 June 2021

*Corresponding author sasa@puterabatam.ac.id

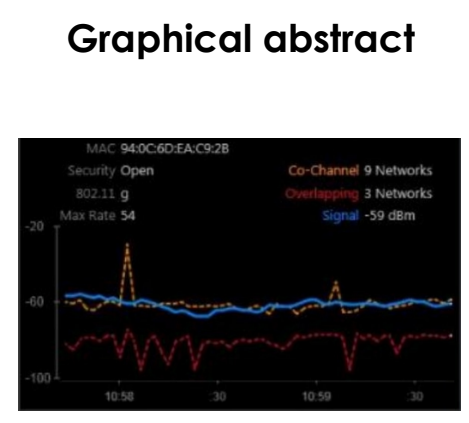

\begin{abstract}
The wireless network adapter has now been widely developed. The wireless adapter receives signal strength has several levels. It depends on the signal strength of the device with respect to the wireless signal and access point. The external adapter is used by computers that are not equipped with a wireless network adapter. Usually, internet users use a USB wireless adapter. An external adapter can also amplify signal reception from hotspots. The problem is how users consider using an external wireless adapter or just an onboard wireless adapter when there are many networks interfering with the weak signal strength of the access point. The method is implemented by measuring the value of the Received Signal Strength Indicator (RSSI). The purpose of this study is to compare the received signal strength in conditions where the signal before interference and after experiencing interference (interference). Meanwhile, the measured RSSI value is divided into four floors and with different distances for each floor. Each floor is measured by five distances. The average value of signal strength at a distance of 10 meters is $-74 \mathrm{dBm}$ using the onboard wireless adapter and $-69 \mathrm{dBm}$ using a USB wireless adapter. The value obtained after the interference is $-75 \mathrm{dBm}$ and the USB wireless adapter gets $-61 \mathrm{dBm}$. The reduction of the RSSI value between interference and non-interference is $3 \%$. The onboard wireless adapter is affected by interference while the external wireless adapter is not affected. The onboard wireless adapter suffers a lot of interference especially at a distance of more than 20 meters from the access point.
\end{abstract}

Keywords: RSSI, Interference, adapter, comparison, wireless

(C) 2021 Penerbit UTM Press. All rights reserved

\subsection{INTRODUCTION}

Along with technological developments, wireless technology is now also developing rapidly. Wireless networks allow users to connect to the internet using many types of compatible devices. Wireless LANs play an important role in internet access networks. It is popular because it is easy to use regardless of the complexity of the cable. This role is increasingly important due to the spread of smartphones and tablets [1]. A hotspot network is a wireless communication system that is built so that it can be accessed by everyone in an area where an internet connection can take place wirelessly. Wi-Fi (Wireless
Fidelity) network is an alternative technology and is relatively easy to implement in the work environment. Usually, hotspots are built with an open system, meaning that anyone who needs internet access can directly connect to the wireless system via the hotspot that has been provided.

Indoor localization system is still a big problem in wireless communication [2]. The floor has a large barrier to the spread of Access Point signals, and the signal experiences sudden changes between the 3rd and 2nd floors [3]. Causes of irregular signal strength are reflection, refraction, noise, and line noise [4]. There are several methods of positioning the Access Point (AP) [5], including multi-dimensional RSS feature 
fuzzy mapping and clustering [6], [7]. Correction algorithm localization errors are reduced by more than $60 \%$ from the value of the Received Signal Strength Indicator (RSSI) [8]. The RSSI-based location method is more widely used [9], [10] for example accessing the home system devices [11]. The value of RSSI depends on receiving signal strength. Calculation of distances compared to different distances, measurement errors can be minimized and distances can be calculated faster [12]. Different antenna angles can have a large impact at distances between $3 \mathrm{~m}$ and $5 \mathrm{~m}$. Judging from the location for the research scenario can also have a major impact [13]. Many hotspots have been applied in various strategic locations such as offices, malls, cafes, and others. In these places, visitors are usually free to use internet access for free even though some are paid. Communication network services in the form of public wireless services have developed a lot of the development of prototypes of CIN AP devices made by Raspberry Pi boards and performance evaluation of multi-hop wireless LANs built by AP prototype devices [14].

To connect to a hotspot network, it requires a device called a wireless adapter. In general, laptops have included a wireless adapter. So that no additional wireless adapter is needed. While desktop computers are very dependent on the type and brand of the motherboard. Wireless adapters are devices that are used by clients to receive and transmit signals. Wireless adapters have a working principle that is almost the same as with an access point, but simpler.

Signal strength is often a problem in accessing the internet. The hotspot signal will be received by the onboard wireless adapter if it is still in close proximity. RSSI can be identified by many factors. Wireless Sensor Network has found its application in many domains [15]. In the WSN (Wireless Sensor Network) factors such as access node transmission, antenna type, distance. While environmental factors such as temperature and humidity [16]. The signal strength will decrease if the adapter farther from access point. At a different height of the receiving antenna $0.5 \mathrm{~m}$, it has decreased by about $10 \%$ [17]. Wireless sensor networks (WSN) are usually used for localization analysis. Through sniffing, then receiving signal strength indication (RSSI) in the WSN system, localization of the higher RSSI is connected automatically [18]. To capture the strength of the hotspot signal, generally use an additional external adapter called USB external wireless. USB wireless adapter is an external wireless that has a form like a flash disk. it can be installed or used on desktop computers or laptops that don't have a device. The difference in the RSSI value on the external wireless adapter with the onboard wireless adapter is a problem for users. It happens when the internet access speed starts to slow down. Lack of knowledge about different RSSI values causes confusion when to use a USB wireless adapter and when to simply use an onboard wireless adapter.
The problem is the difference in RSSI values received by external wireless adapters and onboard wireless adapter in conditions where before being affected by interference and after being affected by interference. Users should consider using an external wireless adapter or just an onboard wireless adapter when there are multiple networks and interfering with the weak signal strength of the access point. The value of RSSI will be recorded by software called InSSIDer which is a software for monitoring wireless networks. The purpose of this study is to compare two wireless adapters where external USB wireless adapter and onboard wireless adapter see the signal strength received in conditions where the signal before interference and after experiencing interference which is measured from four floors and on each floor measured by five distances different. This research is useful for providing references or increasing knowledge that there are differences in RSSI values recorded by each different wireless adapter. In addition, the distance between the adapter and the access point and interference on the same channel can also affect the strength of a signal sent by access points.

\subsection{METHODOLOGY}

\subsection{Wireless}

Wireless is formed by using radio frequency signals as a medium of communication between computers and other network devices. Wi-Fi technology that is implemented is the IEEE $802.11 \mathrm{~g}$ standard because the speed standard is faster for data transfer processes with further network coverage and vendor support (hardware manufacturer companies). The wireless network has a maximum data transfer rate of 54 Mbps. The transmission method used is OFDM. The device works in the $2.4 \mathrm{GHz}$ frequency or referred to as ISM (Industrial, Scientific, and Medical) frequency bands which are also used by other equipment, such as microwave ovens, cordless phones, and Blvetooth. Signal is defined as a physical quantity which is a function of time, space, or several variables. A signal has several types of information that can be observed, such as amplitude, frequency, phase difference, and noise-related interference.

\subsection{Measurement of the Received Signal Strength Indicator (RSSI)}

The received signal can be measured using the RSSI value. RSSI is a measure of the strength of the radio signal received by the receiver. The RSSI value can be obtained when the nodes communicate and the distance between nodes [19]. To measure the value of RSSI, then first calculate the distance from the Access Point to the PC. Besides PC, signal reception can use mobile [20]. The difference in location is adjusted to the difference in the floor of the building. 
Meanwhile, the tools used to receive signal strength are onboard wireless adapter and external wireless adapter. Each floor is measured by different distances with conditions where the RSSI value before interference and the RSSI value after interference. RSSI is a measure of $\mathrm{dBm}$ [21]. The classical theoretical model of RSSI has logarithmic characteristics in the transmission process. The equation is as follows [22]:

$$
\operatorname{RSSI}(\mathrm{d})=\operatorname{RSSI}\left(\mathrm{d}_{0}\right)-10 \mathrm{klog}\left(\mathrm{d} / \mathrm{d}_{0}\right)+\varepsilon .
$$

$\mathrm{d}$ is the distance between the transmitter and receiver; d0 is the known distance; RSSI (d) is the value of signal strength between launch and receive based on distance; $\varepsilon$ is a gaussian random variable; $k$ is the attenuation factor. RSSI will change after the addition of spoofed and the original signal is represented as follows [23]:

$$
R S S I_{T}=\left(P_{S}+P_{G}\right)-10 \lambda \log \left(\frac{d_{S} d_{G}}{d_{0}^{2}}\right)+X\left(\sigma_{S}+\sigma_{G}\right)
$$

Where the RSSIT is interpreted as the total signal strength received. other signals detected and signals used are PS and PG. Distance $d S$ and $d G$ is the distance from the spoofing node and the signal used. $\mathrm{d} 0$ is the reference distance. $X(\sigma S+\sigma G)$ is a Gaussian value that is affected by both signals. General RSSI calculation [24] is as follows:

$$
\text { RSSI=A-10n } \log (d)
$$

Where $A$ is the attenuation of the signal intensity value when the wireless transmitter and receiver are $1 \mathrm{~m}$ away.

\subsection{Interference}

There has been some research on signal interference [25]. Usually packet loss that occurs is caused by interference or commonly called overlapping signals. Signals that are competent in overlapping frequency bands can change or delete signals. Interference is defined as a disturbance that occurs in a wireless signal caused by a channel from an adjacent access point device. In areas that are still lacking in wireless networks, interference is almost certainly nonexistent. There are several methods to solve the problem of signal indicator scattering for indoor localization purposes. They are the Euclidean Distance Matrix (EDM) [26] and the semi-sequential probabilistic model (SSP) [27].

Determining the position of the recipient of the access point is the first to be done to build the quality of RSSI by calculating the distance and coordination [28]. Interference can reduce performance access points in transmitting and receiving signals by reducing the value of RSSI. Access points will lose a few $\mathrm{db}$ if the interface is large. As a result, an error occurs in the bits of information being sent. the recipient's client found the error causing delay or delay in sending even though the error data will be sent again. Interference can also be in the form of Blvetooth signals, cordless telephones (Cordless), Microwave, even electric motorcycles generate noise. Nature can also produce noise such as heavy rain, trees, and sun (on a small scale). Figure 1 shows the capture of signal strength in the form of a wave line.

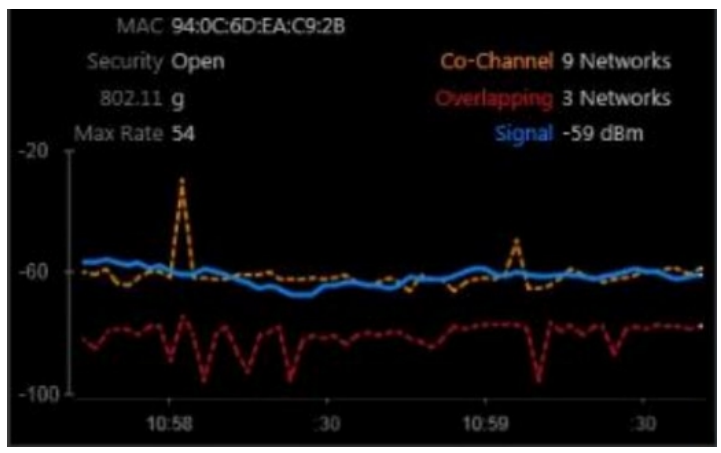

Figure 1 Interference diagram

\subsection{Data Capture Tool}

Some of the tools needed to complete this research are as follows:

- Computer / Laptop with specifications:

a. a. Processor : Intel(R) Core (TM) i5-2410M CPU @2.30GHz (4 CPUs), 2.3GHz

b. Memory: 4.00 GB RAM

c. NIC : Atheros AR9285 Wireless

Network Adapter

- External USB Wireless Adapter

External USB Wireless Adapter is used as an additional adapter to connect to a wireless network. In this study, using an external USB Wi-Fi model TLWN7200ND TP-LINK.

- Software InSSIDer

InSSIDer software is a software used to scan and capture networks with SSID main parameters within the range of computer Wi-Fi antennas. it is also used to track signal strength over time, and determine security settings. The software serves to record the Received Signal Strength Indicator (RSSI) in the study. 


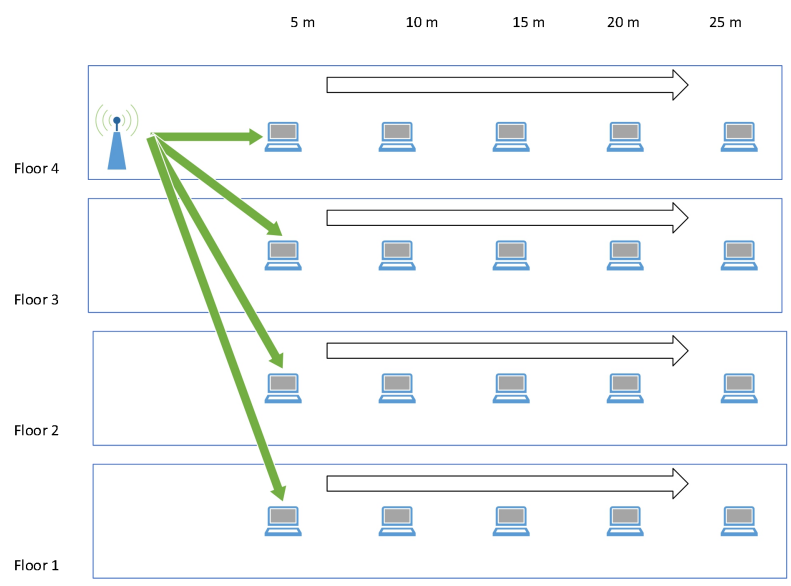

Figure 2 Signal Capture Location

Figure 2 shows how to set up the experimental location. The divider between computers is separated by a brick wall. The height between the floors is 4 meters.

\subsection{RESULTS AND DISCUSSION}

The data in this study were obtained by comparing two wireless adapters with different distances on each floor. Then the signal strength is detected using the InSSIDer and TP-Link Wireless Utility software in $\mathrm{dBm}$ units. At the testing stage the onboard adapter uses InSSIDer and tests external adapters with the TPLink Wireless Utility. The testing phase monitors, records RSSI values and interference values. The RSSI value was taken at the time of the disturbance from the access point called "SPEEDY KAMPUT". the other, the RSSI value is taken without interruption through the access point with the name "My Speedy @ E610". The interference is implemented on the same channel, which is on channel 11.

Signal strength is recorded using software on the fourth floor and distances of 5, 10 and 15 meters respectively where the signal conditions are good before being affected by interference or afterwards. Figure 3 describes the process of recording signal strength based on Laptop Distance to 5 Meter Access Point using two adapters before interference.

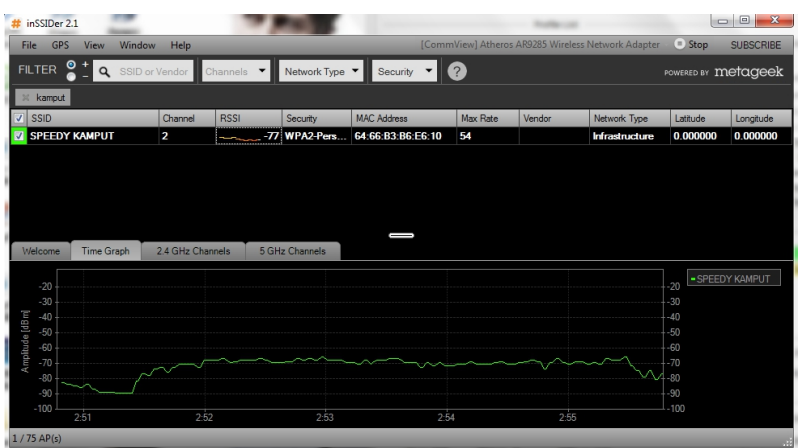

Figure 3 RSSI Performance from a Distance of 5 Meters Without Interference

Figure 4 shows that the results of the experiment on the 4th floor and a distance of 5 meters obtained the RSSI value detected by the InSSIDer software of -70 $\mathrm{dBm}$. While measurements using an external adapter on the 4th floor and a distance of 5 meters get an RSSI value of $-63 \mathrm{dBm}$. Signal strength is still very good.

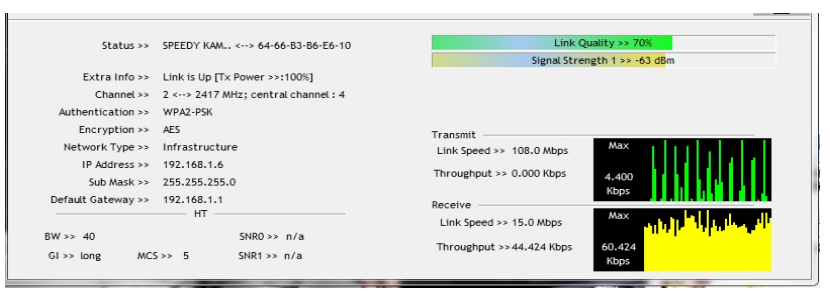

Figure 4 TP-Link in The Experiment is 5 Meters Away and Without Interference

\subsection{Signal Strength Analysis}

Testing two wireless adapters on the same floor and the same distance can be stated that external adapters can better strengthen signal reception than onboard adapters. Table 1 represents the different RSSI values obtained from the experiment using the onboard adapter on each floor and at different distances.

Table 1 RSSI Average Value Results on Onboard Wireless Adapter

\begin{tabular}{|c|c|c|c|c|c|c|}
\hline \multirow{2}{*}{\multicolumn{2}{|c|}{$\begin{array}{l}\text { Wireless Onboard } \\
\text { Adapter }(\mathrm{dBm})\end{array}$}} & \multicolumn{5}{|c|}{ Distances (Meter) } \\
\hline & & \multirow{2}{*}{$\begin{array}{l}5 \\
-70\end{array}$} & \multirow{2}{*}{$\begin{array}{l}10 \\
-74\end{array}$} & \multirow{2}{*}{$\begin{array}{l}15 \\
-89\end{array}$} & \multirow{2}{*}{$\begin{array}{l}20 \\
-89\end{array}$} & \multirow{2}{*}{$\begin{array}{l}25 \\
-95\end{array}$} \\
\hline $\begin{array}{l}\text { 4th } \\
\text { floor }\end{array}$ & $\begin{array}{l}\text { RSSI } \\
\text { (Not } \\
\text { Interference) }\end{array}$ & & & & & \\
\hline & $\begin{array}{l}\text { RSSI } \\
\text { (Interference) }\end{array}$ & -72 & -75 & -81 & -90 & -85 \\
\hline \multirow[t]{2}{*}{$\begin{array}{l}\text { 3th } \\
\text { floor }\end{array}$} & $\begin{array}{l}\text { RSSI } \\
\text { (Not } \\
\text { Interference) }\end{array}$ & -82 & -92 & -93 & - & - \\
\hline & $\begin{array}{l}\text { RSSI } \\
\text { (Interference) }\end{array}$ & -82 & -88 & -92 & - & - \\
\hline \multirow[t]{2}{*}{$\begin{array}{l}\text { 2th } \\
\text { floor }\end{array}$} & $\begin{array}{l}\text { RSSI } \\
\text { (Not } \\
\text { Interference) }\end{array}$ & \multicolumn{5}{|c|}{ Not Detected } \\
\hline & $\begin{array}{l}\text { RSSI } \\
\text { (Interference) }\end{array}$ & \multicolumn{5}{|c|}{ Not Detected } \\
\hline \multirow[t]{2}{*}{$\begin{array}{l}\text { 1th } \\
\text { floor }\end{array}$} & $\begin{array}{l}\text { RSSI } \\
\text { (Not } \\
\text { Interference) }\end{array}$ & \multicolumn{5}{|c|}{ Not Detected } \\
\hline & $\begin{array}{l}\text { RSSI } \\
\text { (Interference) }\end{array}$ & \multicolumn{5}{|c|}{ Not Detected } \\
\hline
\end{tabular}

In the table above, it can be seen that the RSSI value detected by onboard wireless adapter the maximum signal is detected at a distance of 5 meters on the 4th floor and the signal weakens at a distance farther away. On the 3rd floor, the detected signal weakens to a distance of 15 meters. After 15 
meters, the signal is not detected by the onboard adapter again. On the 2nd and 1st floor, the signal is not detected at all by the onboard adapter. The following is a table of RSSI values obtained from experiments using external adapters on each floor and different distances.

Table 2 Average RSSI values obtained on External Wireless Adapter

\begin{tabular}{|c|c|c|c|c|c|c|}
\hline \multirow{2}{*}{\multicolumn{2}{|c|}{$\begin{array}{l}\text { Wireless } \\
\text { Adapter (dBm) }\end{array}$}} & \multicolumn{5}{|c|}{ Distances (Meter) } \\
\hline & & 5 & 10 & 15 & 20 & 25 \\
\hline \multirow[t]{2}{*}{$\begin{array}{l}\text { 4th } \\
\text { floor }\end{array}$} & $\begin{array}{l}\text { RSSI } \\
\text { (Not } \\
\text { Interference) }\end{array}$ & -63 & -69 & -75 & -73 & -77 \\
\hline & $\begin{array}{l}\text { RSSI } \\
\text { (Interference) }\end{array}$ & -61 & -61 & -69 & -82 & -84 \\
\hline \multirow[t]{2}{*}{$\begin{array}{l}\text { 3th } \\
\text { floor }\end{array}$} & $\begin{array}{l}\text { RSSI } \\
\text { (Not } \\
\text { Interference) }\end{array}$ & -75 & -83 & -81 & - & - \\
\hline & $\begin{array}{l}\text { RSSI } \\
\text { (Interference) }\end{array}$ & -77 & -79 & -83 & - & - \\
\hline \multirow[t]{2}{*}{$\begin{array}{l}2 \text { th } \\
\text { floor }\end{array}$} & $\begin{array}{l}\text { RSSI } \\
\text { (Not } \\
\text { Interference) }\end{array}$ & \multicolumn{5}{|c|}{ Not Detected } \\
\hline & $\begin{array}{l}\text { RSSI } \\
\text { (Interference) }\end{array}$ & \multicolumn{5}{|c|}{ Not Detected } \\
\hline \multirow[t]{2}{*}{$\begin{array}{l}\text { 1th } \\
\text { floor }\end{array}$} & $\begin{array}{l}\text { RSSI } \\
\text { (Not } \\
\text { Interference) }\end{array}$ & \multicolumn{5}{|c|}{ Not Detected } \\
\hline & $\begin{array}{l}\text { RSSI } \\
\text { (Interference) }\end{array}$ & \multicolumn{5}{|c|}{ Not Detected } \\
\hline
\end{tabular}

Table 2 describes that the RSSI value detected by the External wireless Adapter on the 4th floor is slightly stronger than using the onboard wireless adapter. On the 2nd and 1st floors, the signal is not detected at all by the external adapter and the onboard wireless adapter.

Based on the data obtained in the table above, it can be represented in Figure 5 . It shows the comparison between the two adapters based on the same floor and different distances.

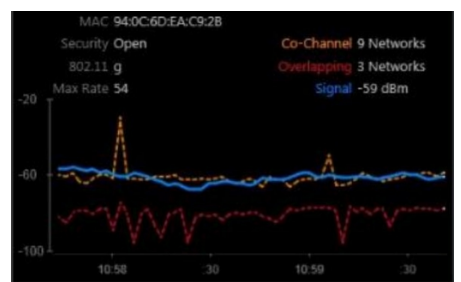

Figure 5 Comparison of 2 Adapters on 4th Floor Without Interference

At Figure 8 it can be seen clearly the difference in signal reception on an external adapter (red line) is stronger than the onboard adapter (blue line) in conditions where there is no interference. The experiment was carried out on the same floor and the same distance.

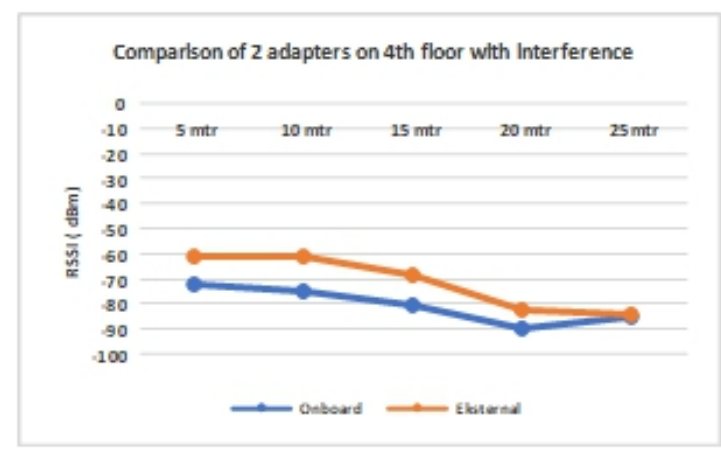

Figure 6 Comparison of 2 Adapters on 4th Floor with Interference

Figure 6 shows that interference affects signal strength when used over short distances. The user's location is further away from the access point, the less the influence of interference.

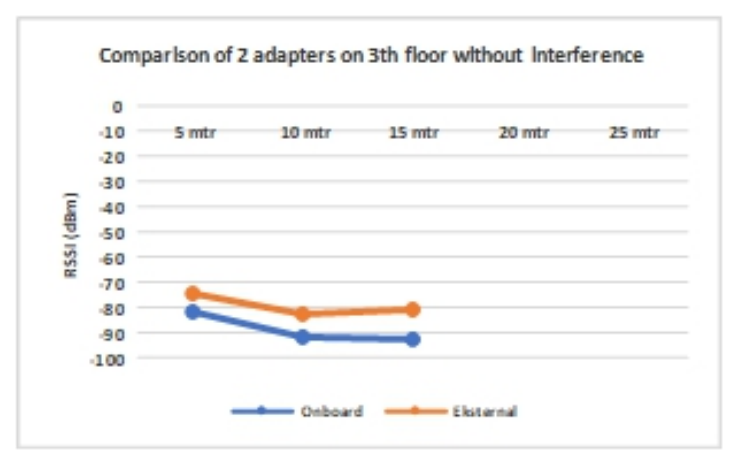

Figure 7 Comparison of 2 Adapters on Level 3 Without Interference

Figure 7 shows that an experiment on two adapters on the 3rd floor without interference still picked up the signal sent at a distance of 5 and 15 meters between the two adapters. A signal is no longer picked up by the onboard and external wireless adapters at a distance of 20 meters.

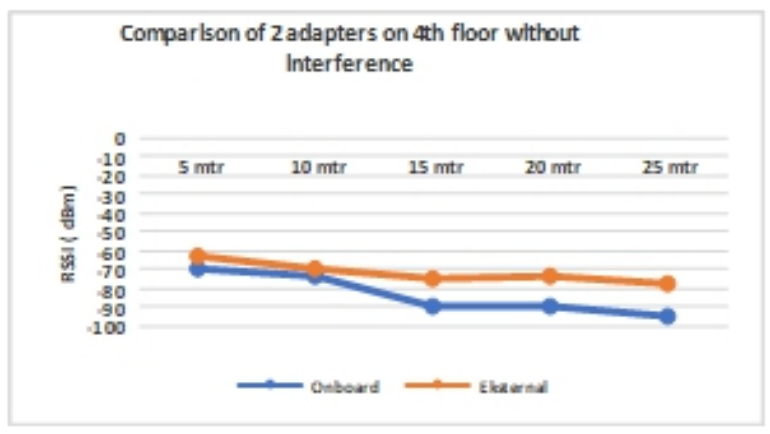

Figure 8 Comparison of 2 Adapters on 3th Floor with Interference 
Based on several experiments, it has been shown that interference has the effect of the signal strength using an onboard or external wireless adapter.

Based on Table 3, it shows that the data obtained shows a difference in the RSSI value of the onboard wireless adapter and the external onboard wireless. The reduction of the RSSI value between interference and non-interference is $3 \%$. The onboard wireless adapter is affected by interference while the external wireless adapter is not affected.

Table 3 Reduction of RSSI

\begin{tabular}{|c|c|c|c|}
\hline \multicolumn{2}{|c|}{} & $\begin{array}{c}\text { Average } \\
(\mathrm{dBm})\end{array}$ & \multirow{2}{*}{ Reduction } \\
\hline $\begin{array}{c}\text { Onboard } \\
\text { Wireless } \\
\text { Adapter }\end{array}$ & $\begin{array}{c}\text { RSSI } \\
\text { (Not Interference) }\end{array}$ & $-85,5$ & \multirow{2}{*}{$3 \%$} \\
\cline { 2 - 3 } & RSSI (Interference) & $-83,125$ & \\
\hline $\begin{array}{c}\text { External } \\
\text { Wireless } \\
\text { Adapter }\end{array}$ & $\begin{array}{c}\text { RSSI } \\
\text { (Not Interference) }\end{array}$ & $-74,5$ & \multirow{2}{*}{$0 \%$} \\
\cline { 2 - 3 } & RSSI (Interference) & $-74,5$ & \\
\hline
\end{tabular}

The signal strength is stronger the closer it gets to $0 \mathrm{dBm}$. This is because it measures the change in the signal from the moment it is transmitted from the base station to the client. Thus, if the signal strength is $-74.5 \mathrm{dBm}$, it means that $-74.5 \mathrm{dBm}$ is less strong when it reaches the mac than when it leaves the base station.

\subsection{CONCLUSION}

Based on the results of testing the comparison of two wireless adapters in the experiment, it can be concluded that the signal strength received by onboard wireless adapter is weaker than the external adapter. The external wireless adapters can amplify signals received within range. The signal strength level received on the onboard and external wireless adapters after interference will be increasingly weak. The signal strength level on external wireless adapters after interference will be weakened, but it is still better than the signal received by the onboard wireless adapter. The reduction of the RSSI value between interference and non-interference is $3 \%$. The onboard wireless adapter is affected by interference while the external wireless adapter is not affected. The solution for interference when there are multiple networks is to use an external wireless adapter. It is more stable than the onboard wireless adapter especially at a distance of $20 \mathrm{~m}$ from the access point.

\section{Acknowledgement}

The authors would like to thank Putera Batam University where it has provided computer lab facilities in construction and experimental support equipment.

\section{References}

[1] T. Nunome, H. Yamamoto, and Y. Honda. 2016. QoE Assessment of a Reliable Groupcast Scheme in Audiovisual Transmission Over a Wireless LAN. Proceedings - 2016 IEEE 8th International Conference on Ubiquitous and Future Networks (ICUFN). 576-581.

[2] T. M. S. Abdulraqeb Alhammadi, Fazirulhisyam Hashim, Mohd Fadlee. 2016. An Adaptive Localization System Using Particle Swarm Optimization in a Circular. J. Teknol. (Sciences Eng.) 3: 105-110.

[3] P. Wang and Y. Luo. 2017. Research on WiFi Indoor Location Algorithm based on RSSI Ranging. Proc. - 2017 4th Int. Conf. Inf. Sci. Control Eng. ICISCE 2017. 2: 16941698.

[4] M. A. Bhatti, R. Riaz, S. S. Rizvi, S. Shokat, F. Riaz, and S. J. Kwon. 2020. Outlier Detection in Indoor Localization and Internet of Things (loT) using Machine Learning. J. Commun. Networks. 22(3): 236-243.

[5] G. Qi, Y. Jin, and J. Yan. 2019. RSSI-based Floor Localization Using Principal Component Analysis and Ensemble Extreme Learning Machine Technique. Int. Conf. Digit. Signal Process. DSP. 2018-Novem.: 1-5.

[6] X. Yang, Z. Liu, W. Nie, W. He, and Q. Pu. 2020. AP Optimization for Wi-Fi Indoor Positioning-Based on RSS Feature Fuzzy Mapping and Clustering. IEEE Access. 8: 153599-153609.

[7] J. Ren, Y. Wang, C. Niu, W. Song, and S. Huang. 2019. A Novel Clustering Algorithm for Wi-Fi Indoor Positioning. IEEE Access. 7: 122428-122434.

[8] J. Xiong, Q. Qin, and K. Zeng. 2015. A Distance Measurement Wireless Localization Correction Algorithm Based on RSSI. Proc. - 2014 7th Int. Symp. Comput. Intell. Des. Isc. 2014. 2(2): 276-278.

[9] S. Liu, F. Wang, and J. Chai. 2016. A Three-dimensional Positioning System based on RSSI for the Wireless Sensor Network. Proc. - 2015 8th Int. Conf. Biomed. Eng. Informatics, BMEl 2015. B(Mei): 768-772.

[10] Y. You and C. Wu. 2020. Indoor Positioning System with Cellular Network Assistance Based on Received Signal Strength Indication of Beacon. IEEE Access. 8: 6691-6703.

[11] V. Bianchi, P. Ciampolini, and I. De Munari. 2019. RSSIBased Indoor Localization and Identification for ZigBee Wireless Sensor Networks in Smart Homes. IEEE Trans. Instrum. Meas. 68(2): 566-575.

[12] O. Ceylan, K. F. Taraktas, and H. B. Yagci. 2010. Enhancing RSSI Technologies in Wireless Sensor Networks by Using Different Frequencies. Proc. - 2010 Int. Conf. Broadband, Wirel. Comput. Commun. Appl. BWCCA 2010. 369-372.

[13] I. G. Tudorache, I. Rasool, and A. H. Kemp. 2012. Indoor RSSI-based Ranging Consistency and Error Factors in Wireless Sensor Networks. 2012 20th Telecommun. Forum, TELFOR 2012 - Proc. 607-610.

[14] A. Ogata et al. 2016. Prototype Development and Performance Evaluation of Wireless LAN Access Points for Community Information Network. IEEE Reg. 10 Annu. Int. Conf. Proceedings/TENCON. 2016-January.

[15] J. Banerjee, M. K. Naskar, U. Biswas, O. Alfandi, and D. Hogrefe. 2014. Leader Selection in Wireless Sensor Networks - An Energy Efficient Approach. Int. Conf. Control. Instrumentation, Energy Commun. CIEC 2014. 508-512.

[16] H. Wang, W. Wang, and H. Zhang. 2014. Human Body Detection of Wireless Sensor Network based on RSSI. 26th Chinese Control Decis. Conf. CCDC 2014. 4879-4884.

[17] M. Lin, B. Chen, W. Zhang, and J. Yang. 2020. Characteristic Analysis of Wireless Local Area Network's Received Signal Strength Indication in Indoor Positioning. IET Commun. 14(3): 497-504.

[18] M. I. Jais et al. 2015. Hardware Comparison Capturing Received Signal Strength Indication (RSSI) for Wireless Sensors Network (WSN). 2015 IEEE Student Conf. Res. Dev. SCOReD 2015. 278-282.

[19] Z. G. Du, J. S. Pan, S. C. Chu, H. J. Luo, and P. Hu. 2020. 
Quasi-affine Transformation Evolutionary Algorithm with Communication Schemes for Application of RSSI in Wireless Sensor Networks. IEEE Access. 8: 8583-8594.

[20] L. Cheng, J. Hang, Y. Wang, and Y. Bi. 2019. A Fuzzy CMeans and Hierarchical Voting Based RSSI Quantify Localization Method for Wireless Sensor Network. IEEE Access. 7: 4741 1-47422.

[21] N. Rosli et al. 2015. Jurnal Teknologi. 1: 1-6.

[22] L. J. Liu and H. J. Ma. 2014. Study on Wireless Sensor Network Boundary Localization based on RSSI. Proc. - 2014 Int. Conf. Wirel. Commun. Sens. Network, WCSN 2014. 232235.

[23] B. Chatfield and R. J. Haddad. 2017. RSSI-based Spoofing Detection in Smart Grid IEEE 802.11 Home Area Networks. 2017 IEEE Power Energy Soc. Innov. Smart Grid Technol. Conf. ISGT 2017.

[24] J. Ren, Y. Wang, W. Bai, C. Niu, and S. Meng. 2017. An
Improved Indoor Positioning Algorithm Based on RSSI Filtering. Proceedings - 2017 17th IEEE International Conference on Communication Technology. 1136-1139.

[25] A. M. Ali et al. 2020. Experimental Investigation of UWB Signal Interference Effect between UWB Communication Device and VSAT. J. Teknol. 82(1): 115-124.

[26] W. Njima, M. Chafii, A. Nimr, and G. Fettweis. 2020. Deep Learning Based Data Recovery for Localization. IEEE Access. 8: 175741-175752.

[27] M. T. Hoang, B. Yuen, X. Dong, T. LU, R. Westendorp, and K. Reddy. 2020. Semi-sequential Probabilistic Model for Indoor Localization Enhancement. arXiv. 20(11): 6160-6169.

[28] Y. Shi, Y. Long, F. Lu, Z. XU, X. Xiao, and S. Shi. 2017. An Indoor RSSI Trilateral Algorithm Considering Piecewise and Space-Scene. Proc. - 2nd IEEE Int. Conf. Smart Cloud, SmartCloud 2017. 15: 278-282. 